Technol, 92, 983 13) Strydom, C. A., et al,, Fuel Process. Technol, 92, 764 14) Duan, Y., et al, Fuel, 90, $974 \quad$ 15) Shi, L., et al, Prepr. Pap.Am.Chem. Soc., Div. Fuel Chem., 56, $344 \quad$ 16) Jie, D., et al., Prepr. Pap.Am.Chem. Soc., Div. Fuel Chem., 56, 321 17) Hsu, C. S., et al., Energy Fuels, 25, 2174 18) Van Niekerk, D., et al., Fuel Process. Technol, 92, 729 19) Van Niekerk, D., et al., Energy Fuels, 25, 2559 20) Chelgani, S. C., et al, Fuel Process. Technol, 92, 349 21) Chaffee, A. L., et al, Prepr. Pap.-Am.Chem. Soc., Div. Fuel Chem., 56, 298 22) Sönmez, ö., et al., Fuel, 90, 2125 23) Xian, L., et al, Prepr.Pap.Am.Chem. Soc., $\begin{array}{lll}\text { Div. Fuel Chem., 56, } 300 & \text { 24) Koyano, K., et al, Energy Fuels, 25, } 2565 & \text { 25) }\end{array}$ Hernandez, M. R., et al, Prepr.Pap.-Am.Chem. Soc., Div. Fuel Chem., 56, 306 26) Murcia, C. F., et al,, Prepr.Pap.-Am.Chem. Soc., Div. Fuel Chem., 56, 304 27) Rahman, M., et al., Prepr. Pap.-Am. Chem. Soc., Div. Fuel Chem., 56, 308 Romanov, V. N., et al., Prepr.Pap.-Am.Chem.Soc., Div. Fuel Chem., 56, 278 29) Zhang, D.-F., et al., Energy Fuels, 25, $1891 \quad 30$ ) Sudibandriyo, M., et al, Energy Fuels, 25, 3355 31) Bhowmik, S., et al, Energy Fuels, 25, $2730 \quad$ 32) Perera, M. S. A., et al, Fuel, 90, $3390 \quad$ 33) Jasinge, D., et al, Fuel, 90, 1292 34) Ranjith, P. G., et al, Fuel, 90, $2751 \quad 35)$ Markevicius, G., et al, Prepr. Pap.Am. Chem. Soc., Div. Fuel Chem., 56, 284 36) Weishauptová, Z., et al., Fuel, 90, 312 37) Sobczyk, J., Fuel, 90, 1018 38) Liu, J, et al, Fuel, 90, 2987 39) Ziarani, A. S., et al, Fuel, 90, $2428 \quad$ 40) Chen, Y., et al., Fuel, 90, 499 41) Pakowski, Z., et al., Fuel, 90, $3330 \quad$ 42) Svábová, M., et al., Fuel, 90 1892 43) Choi, H., et al., Fuel Process. Technol, 92, 2005 44) Tahmasebi, A., et al., Fuel Process. Technol., 90, $1821 \quad$ 45) Qi, Y., et al., Fuel, 90, 1567 46) Yin, S., et al, Fuel Process. Technol, 92, 1554 47) Zhou, Z., et al, Energy Fuels, 25, 3590 48) Mathews, J. P., et al., Fuel Process. Technol, 9258 49) Shurtz, R. C., et al., Energy Fuels, 25, $2163 \quad$ 50) Li, S., et al, Prepr. Pap.-Am. Chem.Soc., Div. Fuel Chem., 56, 279 51) Li, S., et al, Prepr.Pap.Am.Chem.Soc., Div. Fuel Chem., 56, $281 \quad$ 52) Wang, Z., et al, Fuel, 90, $305 \quad$ 53) Wang, Z., et al, Fuel Process. Technol, 92, 1830 54) Redlich, P. J., et al,, Prepr. Pap.Am. Chem. Soc., Div. Fuel Chem., 56, 342 55) Andrews, A. B., et al., Energy Fuels, 25, 3068 56) Yue, X.-M.., et al,, Prepr.Pap.-Am.Chem. Soc., Div. Fuel Chem., 56, 312 57) Sun, B., et al,, Prepr. Pap.Am.Chem. Soc., Div. Fuel Chem., 56, 358 58) Guo, Z., et al, Fuel Process. Technol., 92, 119 59) Bai, Z., et al, Prepr.Pap.-Am.Chem. Soc., Div. Fuel Chem., 56, 317 60) Yang, Q., et al., Energy Fuels, 25, 2119 61) Wang, L., Prepr. Pap.-Am.Chem. Soc., Div. Fuel Chem, 56, 374 62) Corporan, $\begin{array}{lll}\text { E., et al., Energy Fuels, 25, } 955 & \text { 63) Nonaka, M., et al., Fuel, 90, } 2578 \quad \text { 64) }\end{array}$ Anderson, K. B., Prepr. Pap.Am.Chem. Soc., Div. Fuel Chem., 56, 310 65) Green, U., et al, Energy Fuels, 25, $5626 \quad$ 66) Green, U., et al, Energy Fuels, 25, 4211 67) Taraba, B., et al., Fuel, 90, 2790 68) Taraba, B., et al., Fuel Process. Technol, 92, 712 69) Yossifova, M. G., et al., Fuel Process. Technol, 92, 825 70) Bolin, T., Prepr. Pap.-Am. Chem. Soc., Div. Fuel Chem., 56, 57 71) Zhong, S.T., et al, Energy Fuels, 25, 3687 72) Chehreh Chelgani, S., et al, Fuel, 90 , 3156 73) Mochizuki, Y., et al., Fuel, 90, 2974 74) Shen, Y., et al, Energy Fuels, 25, 2963 75) Shen, Y., et al, Energy Fuels, 25, 5007 76) Marinov, S. P., et al, Fuel Process. Technol., 92, 2328 77) Gonsalvesh, L., et al, Fuel, 90, 2923 78) Aytar, P., et al., Fuel Process. Technol., 92, 71 79) Wang, X., et al., Fuel, 90, 248 80) Golda, M., et al, Fuel Process. Technol., 92, 1230 81) Kunli, L., Energy Fuels, 25, $4479 \quad$.82) Ward, C. R., et al, Fuel Process. Technol., 92, 817 83) Saikia, B. K., et al., Fuel Process. Technol., 92, 1068 84) Jorjani, E., et al, Fuel Process. Technol, 92, 1898 85) Samanli, S., Fuel, 90, 659
86) Sahoo, B. K., et al., Fuel Process. Technol., 92, 1920 87) Wijaya, N., et al, Fuel Process. Technol., 92, 2127 88) Wijaya, N. A., et al, Prepr.Pap.Am.Chem. Soc., Div. Fuel Chem., 56, $361 \quad$ 89) Wijaya, N., et al, Energy Fuels, 25, 1

\section{3 石炭の加工と輸送技術}

\section{1. 乾式選炭}

\subsection{1 コールクリーニング}

FGX Dry Separator は $6 \mathrm{~mm}$ 以下の石炭（10-20 wt\%）を流 動媒体として用いエアテーブルの原理で選別を行うもので, 中国などで導入されている。Zhang らはー $63.5+4.75 \mathrm{~mm} の$ イリノイ炭の FGX (10 tph) での最適処理条件を検討し, 脱 灰・脱硫性を評価した。細粒群の存在が選別成績を向上させ ることが知られているが, $-4.75 \mathrm{~mm}$ 粒群の増大が灰分除去 に効果があったものの, 脱硫にはあまり効果は見られなかっ た1)。中国では，1億 3 千万トンの石炭をエアテーブルや流動 層などの乾式選炭で処理している2)。ケンタッキー大学では一 $50+6.3 \mathrm{~mm}$ 粒群のパイロットスケールでのエアテーブル試 験を実施してきたが，Patilらは細粒群 $(-6.3 \mathrm{~mm}+1.4 \mathrm{~mm})$ の処理においても良い脱灰・脱硫成績が得られる条件を見出 した 2)。Sahuらは，マグネタイトを流動媒体とする流動層型 選別機（Air dense medium fluidized bed separator）での流動 層の安定性や- $25+6 \mathrm{~mm}$ 粒群の処理に及ぼす操作因子の影 響を調ベ，スケールアップ試験 $(600 \mathrm{~kg} / \mathrm{h})$ を行った ${ }^{3)}$ 。Zhao らは，流動媒体であるマグネタイトの代替として飽和磁化が 高く, 保持力が低い特性を持ち, 安価・低比重の中国産ペー ジャイト $(-0.3+0.075 \mathrm{~mm})$ を検討し, $-13+6 \mathrm{~mm}$ の石 炭を精度よく分離できることを報告した4)。石炭は摩擦により 正に，脈石は負に带電することを利用して，Taoらはロータ リ一帯電型静電選別機を開発し, 石炭と脈石の比重や濡れ性の 差が少ない微粉炭 $\left(\mathrm{D}_{50}=25 \mu \mathrm{m}\right)$ を処理し, 浮選によるリリー スアナリシス試験および浮沈分析試験の結果と比較した ${ }^{5)}$ 。浮 選よりも良い結果が得られること, 浮沈試験よりも高い脱灰 率が得られることを報告した。

\section{2. 湿式選炭，特性分析}

Firthらは，マグネタイトに非マグネタイト（微細な粘土や 石炭）を混合し，パイロットスケールの重液サイクロン成績 に及ぼす影響を調べた ${ }^{6)}$ 。重液比重 1.4 以下での処理では非マ グネタイト成分が重液の安定性に寄与すること, 重液比重の 低下効果があることなどを示した ${ }^{6 !}{ }^{7)}$ ) Ahmed は，石炭と石 英の混合試料のHarz ジグの結果をYate's分析を用い統計学的 に処理し，最適処理条件や各因子の及ぼす影響を述べた ${ }^{8)}$ 。 Pineres らは，4炭種について pH や捕収剤濃度を変化させて 接触角や表面電位を測定し, 浮選での気泡一粒子間に働く力 を拡張DLVO理論で表し，比較した ${ }^{9)}$ 。Kurniawanらは， $\mathrm{MgCl}_{2}$, $\mathrm{NaCl}, \mathrm{NaClO}_{3}$ の塩水中での浮選を検討し, ダウフロス 250 存 在下では塩の種類によるが, 気泡粒径の減少や合一速度低下 
効果があり，回収率が増大することを報告した ${ }^{10)}$ 。Zhang ら は，遠心比重選別機（薄流型）であるファルコン選別には フィード粒径の制御が効果的であることを述べ, ウレタンス クリーンからなるStack sizer篩分け機でー $75 \mu \mathrm{m}$ を効果的に 除去することで選別成績が向上すること, 脱硫にも効果があ ること, サイクロンサイズ分級使用時とのコスト比較などを 行った ${ }^{11)}$ 。Liuらは，2種の中国炭中の水銀の形態分析を行い, 黄鉄鉱に随伴する水銀が多いこと, 浮沈分析や顕微鏡観察に より微粒の黄鉄鉱が多い石炭は比重選炭での脱水銀が困難で あることなどを報告した ${ }^{12)}$ 。Graham らは, Coal grain analySisによるマセラルや鉱物観察，単体分離性や比重選炭性を予 測する分析を取り入れ，CWM製造のための最適石炭の選定法 を開発した ${ }^{13)}$ 。

\section{文 献：References}

$\begin{array}{ll}\text { 1) Zhang, B. et. al., Int. J.Coal Prep. and Util,, 31, } 161 & \text { 2) Patil, D. P. et. al,, Int. }\end{array}$ J.Coal Prep. and Util., 31, $203 \quad$ 3) Sahu A. K., et. al., Int.J.Coal Prep. and Util., 31, 127 4) Zhao Y. M. et. al., Int.J. Coal Prep. and Util., 31, 149 5) Tao D., et. al., Int.J. Coal Prep. and Util, 31, $187 \quad$ 6) Firth B., et. al, Int.J.Coal Prep. and Util., $\begin{array}{llll}31,346 & 7) \text { Firth B., et. al, Int.J. Coal Prep. and Util, } 31,355 & \text { 8) Ahmed, M. }\end{array}$ M., Int. J. Coal Prep. and Util., 31, 112 9) Pineres, J. et. al., Int.J. Miner. Process., 100, 14 10) Kurniawan, A. U. et. al,, Int. J. Miner. Process., 98, 137 11) Zhang, B. et. al, Int.J. Coal Prep. and Util., 31, 78 12) Liu, H. Y. et. al, Int.J.Coal Prep. and Util, 31, $20 \quad$ 13) O' brien, G. et. al, Int. J. Coal Prep. and Util, 31, 96

\subsection{2 石炭の粉砕}

石炭の粉砕前にマイクロ波を照射して粉砕性を向上させる 研究が続けられている。石炭中の鉱石分, 内蔵水分が石炭分 に比較し, マイクロ波の吸収性が高いことから成分変化, 膨 張などにより，微小クラック，欠陥が生じ粉砕性が向上する とされている。

灰分が多いインド炭について，灰分 $38 \% ， 32 \%$ ，粒度 19.05 〜 $12.7 \mathrm{~mm}$ を試料として，マイクロ波オーブン $(2.45 \mathrm{GHz}, 900$ W) で処理した研究がある。マイクロ波処理済み試料ついて SEM観察, XRD回析, 工業分析, 元素分析, HGI, Wiの測定, 粉砕速度比の算出などを行っている。微細クラックの発生，鉱 物質の変化, 灰分の低減, 粉砕性の向上があることを示して いる1)。

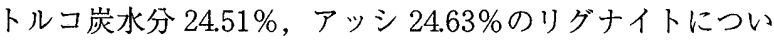
て，マイクロ波処理の研究がある。3,350 $\mu \mathrm{m}$ 以下の細かい石 炭について, 粒度別にマイクロ波で処理した試料と未処理試 料を擋找ミルで粉砕し，粉砕速度比，およびー $105 \mu \mathrm{m}$ 生成 量を比較している。マイクロ波処理した試料は，未処理試料 に比し, HGIが大きく, 粗い試料ほど, 粉砕速度比が大きく, 一 $105 \mu \mathrm{m}$ 生成量も多くなっている ${ }^{2)} 。$

擋拌ミルで低質炭を粉砕し，粉砕速度式によって，ミル機 能を解析した研究がある。供給試料の粒度によって粉砕速度 比が変化し, ボール径 $6 \mathrm{~mm}$ の場合, ボール径と粒子径比は 約 40 が最も粉砕速度比が大きくなり，擋拌ミルは微粉砕に適 しているとしている3)。
石炭中の可燃分，灰分などと粉砕性についての研究がある。 硬度計を使って荷重-変位図から力学特性を把握し粉砕性に影 響する因子を明らかにする可能性について述べている4)。

石炭火力発電所では，需給の逼迫を背景に，HGI の低い亜 瀝青炭などの利用が進められているが, HGI が高い瀝青炭と 混炭時の粉砕性について, HGI 測定装置を用いて検討してい る。混炭時の HGIは単味の值の加重平均值より低く, 粉砕が 進と低 HGI 石炭単味の粉砕性より低くなっている5)。

また石炭火力発電所では, 石炭と木質バイオマスの混焼が行 われている。木質ペレットについてボールミル粉砕でー $74 \mu \mathrm{m}$ 生成率から原料の粒度毎の粉砕性を算出し, 原料の大きさ，樹 種，部位の粉砕性を比較している6)。原料粒径に大きく影響さ れ，また部位より樹種の影響が大きいとしている。

コーク炬において，高膨張圧炭のみを微粉砕後，混炭する 方法によって，押出電流の増大，押詰まり，炉壁の損傷など のトラブルを防ぎ，炉寿命を延ばすことができるとする報文 がある7゙。

\section{文 献: References}

1) Sahoo, B. K., Fuel Processing Technology, 92, 1920-1928 2) Samanli, S., Fuel, 90, 659-664 3) Samznli, S.m Energy Sources, PartA, 33, 549-561 4) 日恵井佳子, 粉体工学会夏期シンポジウム講演論文集 47th, 11-12 5) 星野明宏, 日本エネルギー学会石炭科学会議発表論文, 48th，34-35 6) 板倉優，バイオマス科学会議発表論文集，6th，32-33 7) Nomura, S., ISIJ International, 51, 1425-1431

\subsection{3 スラリー化・輸送}

石炭スラリー化・輸送に関する研究は，近年国内では下火 になっており，新しい研究報告はほとんどみられない。海外 では，従来の石炭スラリーの開発によって蓄積された技術を 応用して, 石炭以外の炭素資源であるバイオマスや污泥ス ラッジなどの廃棄物をスラリー燃料化する技術開発が目立つ ようになった。Parkら ${ }^{1)}$ は, 下水污泥スラッジを水熱処理し 石炭一水スラリーに混合して, 石炭一スラッジ-水スラリーを 調製すると，石炭スラリーのレオロジー特性が改善されたと 報告している。Wang (2) $^{2}$ ，生下水スラッジを石炭-水スラ リーに混合すると，レオロジー特性が向上したと報告してい る。GaOら ${ }^{3)}$ は, 粉体化した石炭ピッチを用いて石炭ピッチー 水スラリーの調製を, Chen ら ${ }^{4)}$ は，豪州オイルマリーバイオ マスチャーや亜炭チャーと水を混合してスラリーを調製する ことを検討している。従来の石炭-水スラリーに関しては，中 国，韓国等で盛んに研究され，Zhang ら5)は，石炭粉砕プロ セスが石炭一水スラリーの特性に与える影響を検討しており， Zhou ら ${ }^{6)}$ は，表面に親水性官能基を含む中国産 Shangwan 炭 に対して，界面活性剤を用いる石炭表面改質を行うと，石炭一 水スラリーの性状が向上したと報告している。Sahooら ${ }^{7)}$ は, マイクロウエーブ照射により高灰分のインド炭を前処理して， 石炭一水スラリーのレオロジー特性を改善することを検討して いる。また，関連技術としてChoiら ${ }^{8)}$ は，神戸製鋼が開発し た油中脱水技術を用いて改質した褐炭の水分再吸着および低 